\title{
Glucagon-like Peptide 1 Enhances Glucose Tolerance Both by Stimulation of Insulin Release and by Increasing Insulin-independent Glucose Disposal
}

\author{
David A. D'Alessio, Steven E. Kahn, Charles R. Leusner, and John W. Ensinck \\ Division of Endocrinology, Metabolism, and Nutrition, Department of Medicine, University of Washington and Veterans Affairs Medical \\ Center, Seattle, Washington 98195
}

\begin{abstract}
Glucagon-like peptide 1 [7-36 amide](GLP-1) has been shown to enhance insulin secretion in healthy and type II diabetic humans, and to increase glucose disposal in type I diabetic patients. To further define its action on glucose kinetics, we studied six healthy subjects who received either GLP-1 (45 pmol/ kg per h) or $150 \mathrm{mM}$ saline on two mornings during which a modified intravenous glucose tolerance test was performed. Plasma insulin and glucose levels were analyzed using Bergman's minimal model of glucose kinetics to derive indices of insulin sensitivity $\left(S_{1}\right)$ and glucose effectiveness at basal insulin $\left(S_{G}\right)$, the latter a measure of glucose disposition independent of changes in insulin. In addition, basal insulin concentrations, the acute insulin response to glucose $\left(A I R_{g}\right)$, plasma glucagon levels, and the glucose disappearance constant $\left(K_{\mathrm{g}}\right)$ were measured on the days that subjects received GLP-1 or saline. Compared with saline infusions, GLP-1 increased the mean $K_{\mathrm{g}}$ from $1.61 \pm 0.20$ to $2.65 \pm 0.25 \% / \mathrm{min}(P=0.022)$. The enhanced glucose disappearance seen with GLP-1 was in part the result of its insulinotropic effect, as indicated by a rise in $\mathrm{AIR}_{\mathrm{g}}$ from $240 \pm 48$ to $400 \pm 78 \mathrm{pM}(P=0.013)$. However, there was also an increase in $S_{G}$ from $1.77 \pm 0.11$ to $2.65 \pm 0.33 \times$ $10^{-2} \cdot \min ^{-1}(P=0.038)$, which was accounted for primarily by insulin-independent processes, viz glucose effectiveness in the absence of insulin. There was no significant effect of GLP-1 on $S_{I}$ or basal insulin, and glucagon levels were not different during the glucose tolerance tests with or without GLP-1. Thus, GLP1 improves glucose tolerance both through its insulinotropic action and by increasing glucose effectiveness. These findings suggest that GLP-1 has direct effects on tissues involved in glucose disposition. Furthermore, this peptide may be useful for studying the process of insulin-independent glucose disposal, and pharmacologic analogues may be beneficial for treating patients with diabetes mellitus. (J. Clin. Invest. 1994. 93:2263-2266.) Key words: incretin hormones • enteroinsular axis • glucose effectiveness $\bullet$ insulin secretion $\bullet$ minimal model
\end{abstract}

\section{Introduction}

Glucagon-like peptide 1 [7-36 amide $_{2}$ ] (GLP-1 $)^{1}$ is an insulinotropic peptide cleaved from proglucagon in epithelial endo-

Portions of this work were presented as an abstract at the International Symposium on Glucagon-like Peptide 1, 17-19 May 1993, Copenhagen, Denmark.

Address correspondence to David A. D'Alessio, M.D., Department of Medicine, RC-14, University of Washington, Seattle, WA 98195.

Received for publication 23 August 1993 and in revised form 28 December 1993.

J. Clin. Invest.

(c) The American Society for Clinical Investigation, Inc.

0021-9738/94/05/2263/04 \$2.00

Volume 93, May 1994, 2263-2266 crine cells in the distal intestine $(1,2)$. GLP-1 release into the circulation is stimulated by ingestion of a glucose or mixed meal, and plasma levels rise concurrently with insulin and glucose, suggesting that this peptide acts as an incretin, a nutrientstimulated hormone that augments insulin secretion $(3,4)$. Parenteral infusion of GLP-1 into healthy humans and patients with type II diabetes mellitus causes a rise in glucosestimulated insulin secretion, and suppresses glucagon release (5). These combined effects of GLP-1 on islet function in diabetic subjects are unique among the gastrointestinal peptides and raise the possibility that this peptide or analogues have potential in the treatment of type II diabetes.

It has recently been reported that infusions of GLP-1 into diabetic subjects decreased the insulin dosage required to maintain euglycemia (6). Furthermore, type I diabetic subjects treated with GLP-1 during one-step euglycemic, hyperinsulinemic clamps had 10-15\% higher rates of glucose disposal than during control studies, thereby suggesting that GLP-1 may promote glucose uptake in addition to augmenting insulin release (6). However, it cannot be determined from these data whether GLP-1 exerts an effect on insulin sensitivity, or if it promotes insulin-independent glucose disposition. Furthermore, because glucose disposal rates were studied only in diabetic subjects, it is not known whether their augmentation by GLP-1 occurs in healthy people, and thus might comprise a physiologic function of this peptide. To more fully assess these putative extrapancreatic actions, we have studied the influence of GLP-1 on intravenous glucose tolerance and its major parameters-insulin secretion, insulin sensitivity, and glucose effectiveness-in healthy nondiabetic subjects.

\section{Methods}

Six healthy persons (five male and one female), ages 24-51 yr, who were weight-stable within $15 \%$ of ideal body weight and had no personal or family histories of diabetes mellitus were recruited. Subjects signed an informed consent form approved by the Human Subjects Committee at the University of Washington. Each subject was studied after an overnight fast on two occasions with assignment to either the experimental or control protocols alternated so that three subjects received GLP-1 and three received saline during their first study. After the withdrawal of three fasting blood samples, each was infused with $\mathrm{NaCl}(150 \mathrm{mM})$ or GLP-1 $(45 \mathrm{pmol} / \mathrm{kg}$ per h$)$ for $4 \mathrm{~h}$; this rate of GLP-1 infusion has been shown previously to cause circulating levels to be elevated two- to threefold greater than the peak concentrations achieved after stimulation by nutrients ( 6 ). GLP-1 was synthesized by solid phase methods at the Howard Hughes Medical Institute, Univer-

1. Abbreviations used in this paper: $\mathrm{AIR}_{\mathfrak{B}}$, acute insulin response to glucose; BIE, basal insulin effect; GEZI, glucose effectiveness at zero insulin; GLP-1, glucagon-like peptide 1 [7-36 amide]; HGO, hepatic glucose output; IVGTT, intravenous glucose tolerance test; $K_{\mathbf{g}}$, glucose disappearance constant; $S_{I}$, insulin sensitivity index; $S_{G}$, glucose effectiveness at basal insulin. 
sity of Washington, and purified by three sequential passages of reverse-phase HPLC; purity was documented by amino acid sequencing and mass spectrometry. Blood was obtained 40, 50, and $55 \mathrm{~min}$ after starting the GLP-1 or saline infusions before administration of an intravenous bolus of glucose $\left(11.4 \mathrm{~g} / \mathrm{m}^{2}\right.$ body surface area $)$ as the commencement of a frequently sampled modified intravenous glucose tolerance test (7). 20 min after glucose injection, a bolus of tolbutamide $\left(125 \mathrm{mg} / \mathrm{m}^{2}\right)$ was given intravenously and blood samples were obtained for an additional $160 \mathrm{~min}$ at previously defined intervals (7).

Blood was collected into heparinized tubes for insulin and glucose analysis, and into EDTA/aprotinin ( $50 \mathrm{mM} / 500 \mathrm{IU}$ per $\mathrm{ml}$ ) for the measurement of glucagon. After immediate centrifugation, the separated plasma was stored at $-20^{\circ} \mathrm{C}$. Insulin and glucagon levels were measured by specific radioimmunoassays $(8,9)$ and glucose concentrations were determined by the glucose oxidase method.

The insulin and glucose data were analyzed using the minimal model of glucose kinetics developed by Bergman et al. (10) to derive indices of insulin sensitivity $\left(S_{1}\right)$ and glucose effectiveness at basal insulin $\left(\mathrm{S}_{\mathrm{G}}\right)$. Glucose effectiveness at zero insulin (GEZI), a more precise description of insulin-independent glucose disposal was calculated as described by Kahn et al. (11):

$$
\begin{gathered}
G E Z I=S_{\mathrm{G}}-B I E \\
B I E \text { (basal insulin effect) }=\text { basal insulin } \times S_{\mathrm{I}}
\end{gathered}
$$

Basal insulin concentrations were calculated as the mean of the three values measured in the 20 min before the glucose infusion. The acute insulin response to glucose $\left(\mathrm{AIR}_{\mathrm{g}}\right)$ was designated as the mean increment in insulin over the fasting level in the first $10 \mathrm{~min}$ after intravenous glucose. The glucose disappearance constant $\left(K_{\mathrm{g}}\right)$ was derived from the slope of the natural logarithm of the five glucose samples taken 10-19 min after the administration of glucose.

The values of $\mathrm{S}_{\mathrm{I}}, \mathrm{S}_{\mathrm{G}}, K_{\mathrm{g}}, \mathrm{AIR}_{\mathrm{g}}$, GEZI, BIE, and basal insulin measured during the GLP-1 and control infusions were compared using Student's $t$ test for paired data. Fasting glucagon levels were designated as the mean of the three samples taken before the saline/GLP-1 infusions, and these measurements were compared to post-intravenous glucose tolerance test (IVGTT) values using analysis of variance. Data are expressed as the mean \pm SEM.

\section{Results}

Basal insulin and glucose concentrations in the healthy volunteers were indistinguishable on the days they received either saline or GLP-1 (Table I). As shown in Fig. 1, the $K_{\mathrm{g}}$ increased from a mean of $1.61 \pm 0.20 \% / \mathrm{min}$ on the day of saline infusion to $2.65 \pm 0.25 \% / \mathrm{min}$ on the morning the subjects received GLP-1 $(P=0.022)$. The improvement in $K_{\mathrm{g}}$ was accounted for in part by the action of insulin since $\mathrm{AIR}_{\mathrm{g}}$ was increased from $240 \pm 48 \mathrm{pM}$ during the day of the saline control to $400 \pm 78 \mathrm{pM}$ during the GLP-1 infusion $(P=0.013)$ (Fig. 2). However, $S_{I}$ was not changed significantly by GLP-1 (Table I), suggesting that the improvement in glucose tolerance was not caused by an independent effect of GLP-1 on the tissue response to insulin. By contrast, $S_{G}$ was elevated by $\sim 50 \%$ when the subjects received GLP-1 (Fig. 3), an increase caused by insulin-independent glucose disposition, since GEZI was increased without a significant alteration in BIE (Table I).

Fasting glucagon levels in the six volunteers were comparable on the days they received GLP-1 and saline (13 11.2 vs 11.8 $\pm 1.7 \mathrm{pM}$; Fig. 4). From $-60 \mathrm{~min}$ to $0 \mathrm{~min}$ the GLP-1 infusion decreased circulating glucagon by $\sim 15 \%$, from $13 \pm 1.2$ to $11.1 \pm 1.8 \mathrm{pM}$, whereas during the control study concentrations did not change appreciably. After the administration of intravenous glucose glucagon concentrations were de-
Table I. Basal Insulin and Glucose, and Parameters of Glucose Disposal Calculated from IVGTTs in Six Healthy Subjects

\begin{tabular}{|c|c|c|c|c|c|c|}
\hline Subject & Insulin & Glucose & $S_{1}$ & $S_{G}$ & BIE & GEZI \\
\hline & $p M$ & $m M$ & $\times 10^{-5}\left(\mathrm{~min}^{-1} / \mathrm{pM}\right)$ & $\min ^{-1}$ & $\min ^{-1}$ & $\min ^{-1}$ \\
\hline \multicolumn{7}{|l|}{ Saline } \\
\hline 1 & 119 & 4.9 & 6.50 & 0.022 & 0.006 & 0.015 \\
\hline 2 & 57 & 4.2 & 8.70 & 0.018 & 0.004 & 0.013 \\
\hline 3 & 98 & 5.2 & 4.73 & 0.018 & 0.004 & 0.014 \\
\hline 4 & 55 & 5.0 & 7.68 & 0.019 & 0.004 & 0.015 \\
\hline 5 & 110 & 5.5 & 2.50 & 0.013 & 0.002 & 0.011 \\
\hline 6 & 208 & 5.7 & 2.77 & 0.017 & 0.005 & 0.013 \\
\hline Mean & 108 & 5.1 & 5.48 & 0.018 & 0.004 & 0.014 \\
\hline $\mathrm{SE}$ & 23 & 0.2 & 1.05 & 0.001 & 0.001 & 0.001 \\
\hline \multicolumn{7}{|l|}{ GLP-1 } \\
\hline 1 & 131 & 5.0 & 5.25 & 0.031 & 0.006 & 0.025 \\
\hline 2 & 48 & 4.4 & 15.35 & 0.039 & 0.006 & 0.033 \\
\hline 3 & 103 & 4.8 & 5.78 & 0.027 & 0.005 & 0.022 \\
\hline 4 & 110 & 4.9 & 10.78 & 0.023 & 0.010 & 0.013 \\
\hline 5 & 95 & 5.2 & 3.85 & 0.024 & 0.003 & 0.021 \\
\hline 6 & 205 & 5.6 & 1.25 & 0.015 & 0.002 & 0.013 \\
\hline Mean & 116 & 5.0 & 7.05 & 0.026 & 0.005 & 0.021 \\
\hline $\mathrm{SE}$ & 21 & 0.2 & 2.08 & 0.003 & 0.001 & 0.003 \\
\hline$P$ & 0.49 & 0.54 & 0.26 & 0.038 & 0.398 & 0.058 \\
\hline
\end{tabular}
Receiving Either Saline or GLP-1 Infusions

$P$ values are for comparisons of the data from the GLP-1 and saline studies.

creased to similar levels on both study days, and throughout the remainder of the studies glucagon values were comparable during infusion of saline or GLP-1.

\section{Discussion}

These data corroborate previous findings that showed that GLP-1 is a potent enhancer of glucose-stimulated insulin release, but has little effect on $\beta$ cell secretion at basal glucose concentrations ( 3 ). In addition, we have found that in healthy

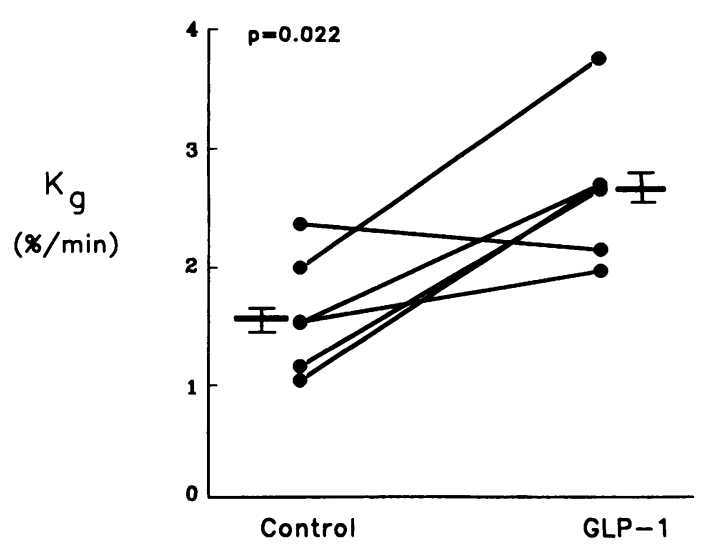

Figure 1. Effect of GLP-1 on glucose disappearance. Mean and individual $K_{\mathbf{z}}$ calculated from IVGTTs in six healthy subjects infused with saline and GLP-1. Bars represent mean $\pm \mathrm{SEM} ; \boldsymbol{P}$ is for comparison of $K_{\mathrm{g}}$ from GLP-1 and control experiments. 


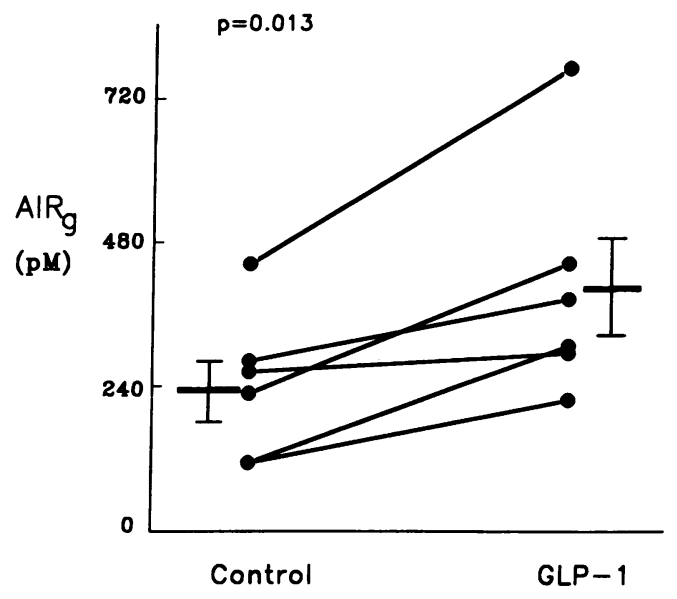

Figure 2. Effect of GLP-1 on glucose-stimulated insulin secretion. Mean and individual $\mathrm{AIR}_{\mathrm{g}}$ calculated for six healthy subjects during IVGTTs with infusions of saline or GLP-1. Bars represent mean $\pm \mathrm{SEM} ; P$ is for comparison of $\mathrm{AIR}_{\mathrm{g}}$ from GLP-1 and control experiments.

humans, GLP-1 stimulates glucose disposal by a mechanism distinct from its effect on insulin secretion, an observation that supports that of Gutniak et al., who showed that GLP-1 promoted glucose uptake in patients with type I diabetes (6). Moreover, our data demonstrate that in nondiabetic individuals, GLP-1 increases glucose effectiveness and insulin-independent glucose disposition without significantly changing insulin sensitivity, a novel finding with both physiologic and therapeutic implications.

The division of glucose disposition into insulin dependent and independent elements has been validated both by modeling and clamp methods $(12,13)$. Insulin-independent glucose uptake, primarily by the central nervous system, is the major component of postabsorptive glucose disposal (14). However, elevations in circulating glucose may also increase glucose uptake by insulin-sensitive tissues, such as skeletal muscle, and suppress hepatic glucose uptake (HGO) independent of changes in insulin levels $(12,13)$. Thus, insulin-independent

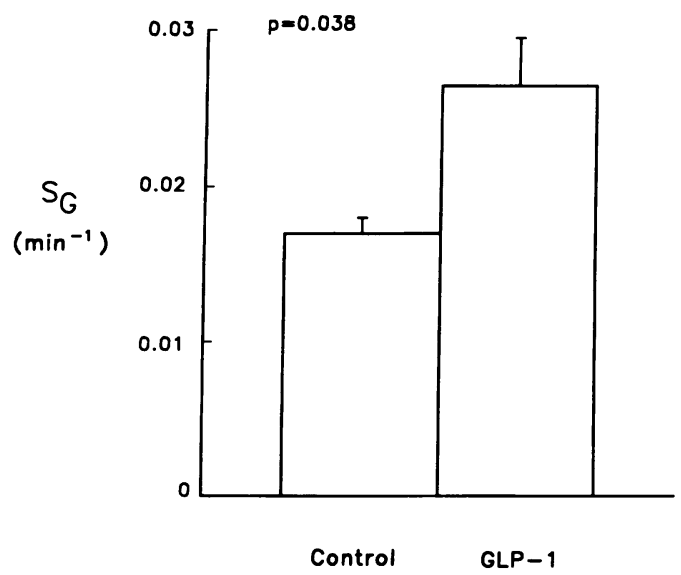

Figure 3. Effect of GLP-1 on $S_{G}$. Mean values of $S_{G}$ in six healthy subjects derived from insulin and glucose data from IVGTTs during infusions of saline or GLP-1. Error bars represent SEM; $P$ is for comparison of $S_{G}$ from GLP-1 and control experiments.

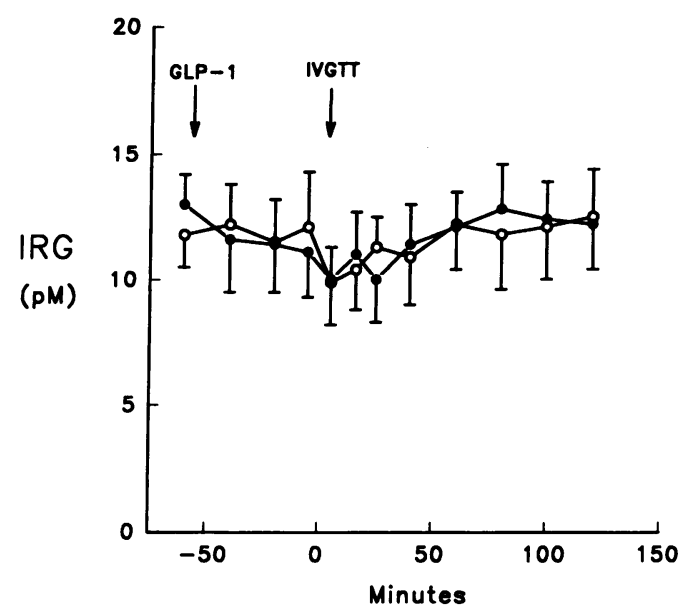

Figure 4. Circulating glucagon concentrations in six healthy subjects during infusions of saline (open circles) and GLP-1 (filled circles), before and after IVGTTs; data points represent mean values \pm SEM.

glucose disposition may play a role in the clearance of glucose after a meal, as well as in the basal state. Glucose effectiveness, as determined by the minimal model, includes both insulin-independent glucose uptake and the effect of hyperglycemia per se to suppress $\mathrm{HGO}$, and so gives a global measure of the effects of changes in glucose concentration on glucose tolerance (13, $15)$. Glucose effectiveness contributes significantly to the maintenance of normal glucose tolerance, and has been estimated to account for $20-25 \%$ of the variance in $K_{\mathrm{g}}$ in healthy individuals (16). Thus, although the methodology used in this study does not allow us to fractionate the improvement of glucose tolerance by GLP-1 into precise insulinotropic and glucose effectiveness-enhancing effects, it can be presumed that these processes are interactive.

It is possible that the increased glucose uptake seen by Gutniak and colleagues in their diabetic subjects infused with GLP-1 during hyperinsulinemic clamps resulted from enhanced glucose effectiveness (6). However, this cannot be discerned from their data, since the increase in glucose uptake they measured may have been caused by either greater insulin sensitivity, enhanced glucose effectiveness, or both. Glucose effectiveness has been shown to be abnormally decreased in both type I and type II diabetic patients $(17,18)$. In addition, it has been reported that in the normoglycemic offspring of couples who both have type 2 diabetes, impairment of glucose effectiveness increases the risk for developing diabetes (19). The specific effect of GLP-1 on glucose effectiveness seen in our nondiabetic subjects raises the possibility that this hormone may stimulate processes that are dysfunctional in the diabetic state.

It has recently been shown that glucose effectiveness and insulin sensitivity are independently regulated so that changes in one of these measures can occur without an alteration in the other $(12,20)$. This independent regulation suggests that different cellular and molecular mechanisms underly these kinetically derived indices. We cannot determine the site where GLP-1 exerts its action to enhance glucose effectiveness, since the indices derived by the minimal model represent whole body glucose kinetics. Augmentation of non-insulin-mediated glucose uptake by hyperglycemia is primarily caused by an increase in glucose uptake by skeletal muscle (12), and it is possi- 
ble that GLP-1 increases glucose effectiveness at this site. The suppressive effect of hyperglycemia on $\operatorname{HGO}(13,21,22)$ is also a component of glucose effectiveness, and GLP-1 may potentiate this action. It is possible that the modest suppression of glucagon levels by GLP-1 before the IVGTT caused a decrease in $\mathrm{HGO}$ and contributed to the greater glucose effectiveness during the GLP-1 infusions. However, glucagon levels were similar throughout the IVGTT in both the GLP-1 and saline studies, making it unlikely that changes in this hormone explain the large increase in the estimate of insulin-independent glucose disposition.

Since it is unlikely that the effect of GLP-1 to increase intravenous glucose tolerance is solely the result of its effect on islet hormone secretion, it is probable that this peptide acts directly on tissues involved in glucose disposition. The GLP-1 receptor has been cloned and an mRNA demonstrated in Northern blots of extracts from isolated pancreatic islets, but not muscle or liver (23). However, kinetic studies with radiolabeled GLP1 have demonstrated specific, saturable binding to adipocyte membranes (24), raising the possibility that GLP-1 may have a role in the regulation of other tissues important in fuel homeostasis. The specific and potent effect of GLP-1 to increase glucose effectiveness may make it a useful tool to study the mechanisms that contribute to insulin-independent glucose metabolism.

In summary, we have shown that intravenous infusion of GLP-1 improves glucose tolerance in healthy humans by increasing insulin secretion and insulin-independent glucose disposition. Because we used a GLP-1 infusion rate that has been reported to raise concentrations in the circulation several-fold over those achieved after eating (6), it is not possible to determine whether this extrapancreatic action of GLP-1 is a pharmacologic or a physiologic effect. Further work with GLP-1 should permit an understanding of this aspect of physiology, as well as provide insights into the regulation of glucose effectiveness, and development of GLP-1 analogues could provide useful agents for the treatment of diabetes.

\section{Acknowledgments}

We thank Ellen Laschansky, Robin Vogel, and Kristin Grant for their technical assistance. This work was carried out on the Clinical Research Center at the University of Washington (RR-0037) and supported by United States Public Health Service Grants DK-03498, DK34397, DK-12829, and DK-17047, and also by the Medical Research Service of the Department of Veterans Affairs. David D'Alessio is a recipient of a New Investigator Award from the Clinical Nutrition Research Unit, grant DK-35816.

\section{References}

1. Drucker, D. J. 1990. Glucagon and the glucagon-like peptides. Pancreas. 5:484-488.

2. Goke, R., H.-C. Fehmanm, and B. Goke. 1991. Glucagon-like peptide(7-36) amide is a new incretin/enterogastrone condidate. Eur. J. Clin. Invest. 21:135-144.
3. Kreymann, B., M. A. Ghatei, G. Williams, and S. R. Bloom. 1987. Glucagon-like peptide 1 (7-36): a physiological incretin in man. Lancet. ii:1300-1303.

4. Orskov, C., J. Jeppesen, S. Madsbad, and J. J. Holst. 1991. Proglucagon products in plasma of noninsulin-dependent diabetics and nondiabetic controls in the fasting state and after oral glucose and intravenous arginine. J. Clin. Invest. 87:415-423.

5. Nauck, M. A., M. M. Heimesaat, C. Orskov, J. J. Holst, R. Ebert, and W. Creutzfeldt. 1993. Preserved incretin activity of glucagon-like peptide 1 [7-36 amide] but not of synthetic human gastric inhibitory polypeptide in patients with type-2 diabetes mellitus. J. Clin. Invest. 91:301-307.

6. Gutniak, M., C. Orskov, J. J. Holst, B. Ahren, and S. Effendic. 1992 Antidiabetogenic effect of glucagon-like peptide-1 (7-36) amide in normal subjects and patients with diabetes mellitus. N. Engl. J. Med. 326:1316-1322.

7. Beard, J. C., R. N. Bergman, W. K. Ward, and D. Porte, Jr. 1986. The insulin sensitivity index in nondiabetic man: correlation between clamp-derived and IVGTT-derived values. Diabetes. 35:362-369.

8. Zaharko, D., and L. Beck. 1968. Studies of a simplified plasma insulin immunoassay using cellulose powder. Diabetes. 17:444-457.

9. Henquin, J. C., P. Malvaux, and A. E. Lambert. 1974. Glucagon immunoassay using polyethelene glycol to precipitate antibody-bound hormone. Diabetologia. 10:61-68.

10. Bergman, R. N., Y. Z. Ider, C. R. Bowden, and C. Cobelli. 1979. Quantitative estimation of insulin sensitivity. Am. J. Physiol. 236:E667-E677.

11. Kahn, S. E., L. J. Klaff, M. W. Schwartz, J. C. Beard, R. N. Bergman, G. J. Taborsky, Jr., and D. Porte, Jr. 1990. Treatment with a somatostatin analog decreases pancreatic B-cell and whole body sensitivity to glucose. J. Clin. Endocrinol. \& Metab. 71:994-1002.

12. Baron, A. D., G. Brechtel, P. Wallace, and S. V. Edelman. Rates and tissue sites of non-insulin and insulin-mediated glucose uptake in humans. 1988. Am. J. Physiol. 255:E769-E774.

13. Ader, M., G. Pacini, Y. J. Yang, and R. N. Bergman. 1985. Importance of glucose per se to intravenous glucose tolerance: comparison of the minimal-model prediction with direct measurements. Diabetes. 34:1092-1103.

14. Owen, O. E., A. P. Morgan, H. G. Kemp, J. M. Sullivan, M. G. Herrera, and G. F. Cahill. 1967. Brain metabolism during fasting. J. Clin. Invest. 46:15891595.

15. Bergman, R. N. 1989. Toward physiological understanding of glucose tolerance: minimal model approach. Diabetes. 38:1512-1527.

16. Kahn, S. E., R. L. Pridgeon, D. K. McCulloch, E. J. Boyko, R. N. Bergman, M. W. Schwartz, J. L. Neifing, W. K. Ward, J. C. Beard, J. P. Palmer, and D. Porte, Jr. 1993. The contribution of insulin independent glucose uptake to intravenous glucose tolerance in healthy human subjects. Diabetes. 43:587-592.

17. Finegood, D. T., I. M. Hramiak, and J. Dupre. 1990. A modified protocol for estimation of insulin sensitivity with the minimal model of glucose kinetics in patients with insulin-dependent diabetes. J. Clin. Endocrinol. \& Metab. 70:15381549.

18. Welch, S., S. S. P. Gebhart, R. N. Bergman, and L. S. Phillips. 1990. Minimal model analysis of intravenous glucose tolerance test-derived insulin sensitivity in diabetic subjects. J. Clin. Endocrinol. \& Metab. 71:1508-1518.

19. Martin, B. C., J. H. Warram, A. S. Krolewski, R. N. Bergman, J. S Soeldner, and C. R. Kahn. 1992. Role of glucose and insulin resistance in development of type 2 diabetes mellitus: results of a 25 -year follow-up study. Lancet. 340:925-929.

20. Kahn, S. E., R. N. Bergman, M. W. Schwartz, G. J. Taborsky, Jr., and D. Porte, Jr. 1992. Short-term hyperglycemia and hyperinsulinemia improve insulin action but do not alter glucose action in normal humans. Am. J. Physiol 262:E518-E523.

21. Sacca, L., R. Handler, and R. S. Sherwin. 1978. Hyperglycemia inhibits glucose production in man independent of changes in glucoregulatory hormones. J. Clin. Endocrinol. \& Metab. 47:1160-1163.

22. Liljenquist, J. E., G. L. Mueller, A. D. Cherrington, J. M. Perry, and D. Rabinowitz. 1979. Hyperglycemia per se can inhibit hepatic glucose production in man. J. Clin. Endocrinol. \& Metab. 48:171-175.

23. Thorens, B. 1992. Expression cloning of the pancreatic $\beta$-cell receptor for the glucoincretin hormone glucagon-like peptide 1. Proc. Natl. Acad. Sci. USA 89:8641-8645.

24. Valverde, I., E. Merida, E. Delgado, M. A. Trapote, and M. L. VillanuevaPenacarrillo. 1993. Presence and characterization of glucagon-like peptide-1 (736 ) amide receptors in solubilized membranes of rat adipose tissue. Endocrinology. 132:75-79. 